\title{
Anti-platelet therapy and endoscopic procedures: eyes wide shut?
}

Authors

Institution
Cesare Hassan, Angelo Zullo

Department of Gastroenterology, ONRM Hospital, Rome, Italy submitted: 23. March 2015 accepted after revision: 6. May 2015

\section{Bibliography}

Dol http://dx.doi.org/ 10.1055/s-0034-1392368

Published online: 24.6.2015

Endosc Int Open 2015; 03: E179-E180

(C) Georg Thieme Verlag KG Stuttgart · New York E-ISSN 2196-9736

\section{Corresponding author}

\section{Cesare Hassan, MD}

Department of

Gastroenterology

ONRM Hospital

Via Morosini 30

Rome 00153

Italy

Fax: +39-06-58446533

cesareh@hotmail.com
That the decision-making process in medicine is generally complex is comprehensible. Indeed, several factors need be considered when a medical procedure is performed or a therapeutic approach is used, such as the patient's characteristics, the complexity of the procedure, the drugs to be administered, the physician's skill, and the setting. The difficulty is further increased when the available scientific data for a specific topic are incomplete or controversial. In this scenario, the existence of official guidelines is surely an advantage for physicians wishing to minimize clinical errors.

The management of antiplatelet agent (APA) therapy before gastrointestinal endoscopy is a typical situation requiring complex analysis in that several factors need to be considered. Fortunately, in 2009, the American Society of Gastrointestinal Endoscopy (ASGE) Standards of Practice Committee delivered recommendations on the management of antithrombotic agents in patients undergoing endoscopic procedures [1]. Basically, the endoscopic examinations were subgrouped as procedures associated with a "low risk" or a "high risk" for bleeding. The recommendations advised that the discontinuation of APA therapy before diagnostic procedures (low risk), as well as before polypectomy, endoscopic retrograde pancreatography (ERCP) with sphincterotomy, stent placement (without dilation), and percutaneous endoscopic gastrostomy (PEG), is not required because no data have consistently demonstrated a significant increase in risk for bleeding [1]. Moreover, no bleeding-related deaths occurred in patients on APA therapy after endoscopic mucosal resection (EMR) or endoscopic submucosal dissection (ESD) [2, 3].

Nevertheless, the question of how these guidelines are followed in clinical practice must be asked. A specific, pretested questionnaire was administered to 400 gastroenterologists attending an ASGE endoscopy course, and 239 of them
(60\%) completed the survey [4]. Surprisingly, as many as $26 \%$ of the endoscopists stated that they withhold all APAs before any endoscopic procedure. Such an approach raises some relevant concerns, which deserve consideration.

As in a movie, we alternately look at a case with the eyes of an endoscopist and with those of a patient. The endoscopist is required to perform an endoscopic procedure in a patient at increased risk for bleeding because of ongoing APA therapy. What are the endoscopist's eyes looking at? Surely, procedure-related bleeding. Therefore, the endoscopist stops the APA therapy for 5 to 7 days before the endoscopic procedure (and for 1 to 5 days afterward) in all patients, particularly when he or she considers that an unplanned operative procedure (e.g., a polypectomy) may be necessary. Although such a cautious approach is also advantageous for the patient, the endoscopist is marginalizing the potential risk to the patient related to the interruption of APA therapy. Indeed, the patient is taking long-term APA therapy for either the primary or the secondary prevention of cardiovascular events. Prevention is primary when a patient has cardiovascular risk factors but has previously had no cardiovascular event, whereas it is secondary when a patient has previously had a myocardial infarction or stroke. What are the patient's eyes are looking at when the interruption of preventive therapy is suggested? Surely, they are imagining a serious cardiovascular event. Most likely, the patient is unaware of the increased risk for bleeding during endoscopy that is related to the ongoing APA therapy. How to balance the caution of the endoscopist and the safety of the patient? Considering that the ideal situation (a zero risk for bleeding and a zero risk for a cardiovascular event) is impossible, a wise approach should be chosen. Fortunately, consistent data are available on the role of APA therapy in the prevention of cardiovascular events. There is clear evidence that the cardiovas- 
Table 1 Annual rates of cardiovascular events in patients receiving primary or secondary prevention with antiplatelet therapy.

\begin{tabular}{|c|c|c|c|c|c|c|c|c|c|c|c|c|}
\hline \multirow[t]{2}{*}{ Setting* } & \multicolumn{6}{|c|}{ Nonfatal myocardial infarction, \% Ischemic stroke, \% } & \multicolumn{3}{|c|}{ Hemorrhagic stroke, \% } & \multicolumn{3}{|c|}{ Major GI bleeding, \% } \\
\hline & ASA & C & OR $(95 \% \mathrm{Cl})$ & ASA & C & OR $(95 \% \mathrm{Cl})$ & ASA & C & OR (95\%Cl) & ASA & C & OR (95\%Cl) \\
\hline $\begin{array}{l}\text { Primary } \\
\text { preven- } \\
\text { tion }\end{array}$ & 0.18 & 0.23 & $0.77(0.69-0.86)$ & 0.10 & 0.11 & $0.86(0.74-1.00)$ & 0.04 & 0.03 & $1.32(1.00-1.75)$ & 0.10 & 0.07 & $1.54(1.30-1.82)$ \\
\hline $\begin{array}{l}\text { Second- } \\
\text { ary pre- } \\
\text { vention }\end{array}$ & 1.66 & 2.34 & $0.69(0.60-0.80)$ & 0.61 & 0.77 & $0.78(0.61-0.99)$ & 0.17 & 0.09 & $1.67(0.97-2.90)$ & 0.11 & 0.03 & $2.69(1.25-5.76)$ \\
\hline
\end{tabular}

Gl, gastrointestinal; ASA, low-dose aspirin; C, control; OR, odds ratio; Cl, confidence interval.

Data were extrapolated from reference 5.

* Primary prevention: in patients with cardiovascular risk factors but without a previous cardiovascular event; secondary prevention: in patients with a previous myocardial infarction or stroke.

cular risks are distinctly different in the settings of primary and secondary prevention [5]. As shown in $\bullet$ Table 1, the risk for ischemic events (myocardial infarction and stroke) without therapy is nearly 10 -fold higher in secondary than in primary prevention ( $3.11 \%$ vs $0.34 \%$ yearly).

Based on these data, APA therapy can be safely interrupted for 5 to 7 days in those patients receiving primary prevention, but not in those receiving secondary prevention. Of note, nearly $70 \%$ of recurrent cardiovascular events develop within 7 to 10 days after the interruption of therapy, suggesting a potential "aspirin withdrawal syndrome" due to a probable rebound in platelet function [6]. Moreover, in a randomized study of patients on APA therapy for secondary cardiovascular prevention in whom endoscopic hemostasis of an actively bleeding peptic ulcer was achieved, it was found that a cardiovascular complication developed in $6.4 \%$ of those receiving placebo, and as many as $60 \%$ of these complications occurred within 10 days [7]. Therefore, even a short interruption of APA therapy is associated with a risk for cardiovascular complications, with potentially life-threatening consequences. Of note, the risk for delayed bleeding requiring re-intervention following colonic polypectomy was $6.4 \%$ in patients taking clopidogrel and $5.5 \%$ in patients taking aspirin $[8,9]$. These rates are very similar to the rate of cardiovascular complications following the withdrawal of APA therapy [7]. However, the clinical consequences are not the same. Indeed, unlike post-procedural bleeding, which is preventable, can be managed successfully in the large majority of cases, and does not cause long-term consequences, a cardiovascular event cannot be prevented, is associated with a high morbidity rate, and may cause irreversible disability. It would be very interesting to know whether the $26 \%$ of endoscopists who stated that they withhold all APAs before any endoscopic examination withhold them from patients undergoing dual therapy with ASA and clopidogrel after the placement of a drug-eluting coronary stent. In these patients, APA interruption is really dreadful. Indeed, operative endoscopy in these patients should be either postponed, when possible, or performed while the patient is on bridging antithrombotic therapy with tirofiban (Aggrastat; Medicure Pharma) in urgent situations [10], but APA interruption must be avoided.

Another relevant finding of this survey is that the endoscopists who stopped APA therapy before any endoscopic examination based the decision on their own experience without witnessing ischemic or bleeding complications, suggesting an "a priori" choice [4]. Probably, the cardiovascular risks related to the interruption of APA therapy, particularly in those patients receiving secondary prevention, were neglected or unjustifiably marginalized by the endoscopists.
At the end of the movie, the endoscopist is seeing "red" (bleeding) and the patient is seeing "black" (dead after a cardiovascular event), leading to the paradox of an "eyes wide shut" scenario. A possible solution is to keep in mind that in secondary cardiovascular prevention, the risk for bleeding related to the continuation of APA therapy before an operative endoscopic procedure is, in absolute terms, equivalent to the risk for a cardiovascular complication. On the other hand, with APA therapy, the patient is already accepting a risk for hemorrhagic stroke ( $0.17 \%$ yearly) similar to that for gastrointestinal bleeding ( $0.11 \%$ yearly; $\bullet$ Table 1 ). Thus, just accept for the gastrointestinal tract the same absolute risk for bleeding that you already accept for the brain, but save the heart!

\section{Competing interests: None}

\section{References}

1 Anderson MA, Ben-Menachem T. AGSE Standards of Practice Committee. et al. Management of antithrombotic agents for endoscopic procedures. Gastrointest Endosc 2009; 70: 1060-1070

2 Burgess NG, Williams SJ, Hourigan LF et al. A management algorithm based on delayed bleeding after wide-field endoscopic mucosal resection of large colonic lesions. Clin Gastroenterol Hepatol 2014; 12: $1525-1533$

3 Repici A, Hassan C, De Paula Pessoa D et al. Efficacy and safety of endoscopic submucosal dissection for colorectal neoplasia: a systematic review. Endoscopy 2012; 44: $137-150$

4 Parasa S, Sinh P, Singh $M$ et al. Wide variations in practice patterns regarding management of anti-platelet agents during endoscopy: results from a nation-wide survey. Gastrointest Endosc 2013; 77: AB474

5 AntithromboticTrialists'(ATT) Collaboration. Baigent C, Blackwell $L$ et al. Aspirin in the primary and secondary prevention of vascular disease: collaborative meta-analysis of individual participant data from randomised trials. Lancet 2009; 373: 1849-1860

6 Biondi-Zoccai GG, Lotrionte M, Agostoni P et al. A systematic review and meta-analysis on the hazards of discontinuing or not adhering to aspirin among 50,279 patients at risk for coronary artery disease. Eur Heart J 2006; 27: 2667-2674

7 Sung JJ, Lau JY, Ching JY et al. Continuation of low-dose aspirin therapy in peptic ulcer bleeding: a randomized trial. Ann Intern Med 2010; 152: $1-9$

8 Gandhi S, Narula N, Mosleh W et al. Meta-analysis: colonoscopic postpolypectomy bleeding in patients on continued clopidogrel therapy. Aliment Pharmacol Ther 2013; 37: 947-952

9 Pan A, Schlup M, Lubcke R et al. The role of aspirin in post-polypectomy bleeding - a retrospective survey. BMC Gastroenterology 2012; 12: 138

10 Savonitto S, Caracciolo M, Cattaneo $M$ et al. Management of patients with recently implanted coronary stents on dual antiplatelet therapy who need to undergo major surgery. J Thromb Haemost 2011; 9: $2133-2142$ 